\title{
Valor energético de alguns alimentos alternativos para codornas japonesas
}

\author{
Márcia Izumi Sakamoto ${ }^{1}$, Alice Eiko Murakami ${ }^{2}$, Luciana Maria Garcia de Souza ${ }^{1}$, José Rodrigo Galli \\ Franco $^{1}$, Luís Daniel Giusti Bruno ${ }^{2}$, Antonio Claudio Furlan²
}

\footnotetext{
1 Pós-Graduação em Zootecnia da Universidade Estadual de Maringá/UEM/Maringá-PR.

2 Departamento de Zootecnia da Universidade Estadual de Maringá/UEM/Maringá-PR.
}

RESUMO - Um ensaio de digestibilidade foi conduzido com o objetivo de determinar o valor energético da aveia, da cevada, do resíduo do processamento de mandioca e da semente de linhaça (inteira e moída) para codornas japonesas (Coturnix coturnix japonica). Foram utilizadas 360 codornas machos, com 40 dias de idade, distribuídas em um delineamento experimental inteiramente casualizado, com seis tratamentos (ração-referência + cinco alimentos), seis repetições e dez aves por unidade experimental. Foi utilizado o método tradicional de coleta total de excretas, em que os alimentos avaliados substituíram em $20 \%$ a ração-referência (RR), à base de milho e farelo de soja. Os coeficientes de metabolização da energia bruta (CMEB) da aveia, da cevada e da semente de linhaça (inteira e moída) foram superiores ao do resíduo de mandioca. Os CMEB (\%) e os valores de energia metabolizável aparente ( $\mathrm{kcal} / \mathrm{kg}$ ) e aparente corrigida para balanço de nitrogênio (kcal $/ \mathrm{kg}$ ) foram, respectivamente, de 75,$37 ; 3.425$ e 3.395 para aveia moída; 75,73; 3.253 e 3.198 para cevada moída; 70,76; 2.312 e 2.316 para resíduo de mandioca; 76,53; 3.774 e 3.704 para linhaça inteira; 76,75; 3.955 e 3.929 linhaça moída.

Palavras-chave: Coturnix coturnix japonica, digestibilidade, energia

\section{Energy value of some alternative feedstuffs for Japanese quails}

ABSTRACT - The objective of this trial was to determine the energy value of oat, barley, cassava residue and linseed grain (whole and milled) for Japanese quails (Coturnix coturnix japonica). Three hundred and sixty 40-d male quails were assigned to a completely randomized design with six treatments (reference diet + five feedstuffs), six replications and ten birds per pen. The total feces collection was the used methodology. The feedstuffs evaluated were used at a level of $20 \%$ replacing the energy source of the reference diet (RD) that was based on corn and soybean meal. The gross energy metabolization coefficient (GEMC) of oat, barley and linseed were higher than the cassava residue. The GEMC (\%), apparent metabolizable energy ( $\mathrm{kcal} / \mathrm{kg}$ ) and apparent correct metabolizable energy values for nitrogen $(\mathrm{kcal} / \mathrm{kg})$ were, respectively: $75.37 ; 3,425$ and 3,395 for oat milled; $75.73 ; 3,253$ and 3,198 for barley milled; 70.76; 2,312 and 2,316 for cassava residue; $76.53 ; 3,774$ and 3,704 for linseed whole; $76.75 ; 3,955$ and 3,929 for linseed milled.

Key Words: Coturnix coturnix japonica, digestibility, energy

\section{Introdução}

A criação comercial de codornas japonesas (Coturnix coturnix japonica) tem por finalidade a produção de carne e, principalmente, de ovos. É um setor da avicultura que está em franco crescimento com grande produtividade e rentabilidade, como conseqüência do rápido crescimento das aves, da maturidade precoce, da alta taxa de postura e do baixo consumo de ração (Murakami \& Furlan, 2002). No entanto, ainda são escassas as informações nas áreas de manejo e nutrição, dificultando a criação e contribuindo para o aumento no custo de produção desta espécie, como por exemplo o fornecimento de rações que não se adequam às reais exigências dessas aves.

De modo geral, a nutrição corresponde a aproximadamente $75 \%$ dos custos de produção na criação de codornas, tornando-se essencial, portanto, sua otimização, por meio da utilização de alimentos alternativos (Furlan et al., 1998), possibilitando a expressão do potencial genético dessas aves. Além da nutrição, programas de melhoramento genético necessitam de maior popularidade, para obtenção de linhagens definidas, garantindo, assim, a produtividade dessas aves (Garcia \& Pizzolante, 2004).

A utilização de alimentos alternativos tem sido constante em rações para frangos de corte e galinhas de postura, mas, na alimentação de codornas, pouco se tem estudado, considerando-se que essas aves apresentam diferenças fisiológicas e comportamentais, diferenciando-se das demais em eficiência alimentar e produtividade (Murakami \& Furlan, 2002).

O tempo de passagem da digesta pelo intestino das codornas é muito rápido, o que influencia a digestibilidade 
de nutrientes e, conseqüentemente, o seu valor energético. Está relacionado também a uma série de variáveis, como composição do alimento e quantidade ingerida (Furlan et al., 1998) e aspecto físico do alimento (Leandro et al., 2001).

Como a energia é um fator nutricional determinante na nutrição animal e que, normalmente, tanto os valores de energia metabolizável (EM) dos alimentos quanto as exigências de EM utilizadas para poedeiras comerciais têm sido utilizados na formulação de rações para codornas e que nem sempre permitem formular dietas que atendam corretamente as exigências destas aves (Furlan et al., 1998), é de extrema importância o conhecimento do verdadeiro valor energético dos alimentos para cada espécie, considerando-se que, na literatura, a maioria das pesquisas é realizada com frangos de corte (Albino et al., 1981, 1985 e 1986; Muztar \& Slinger, 1982; Allen, 1992; Murakami et al., 1995).

No intuito de aumentar os conhecimentos na área de nutrição de codornas, objetivou-se determinar os valores energéticos da aveia, da cevada, do resíduo do processamento da mandioca e da semente de linhaça (inteira e moída) para codornas japonesas.

\section{Material e Métodos}

O experimento foi conduzido no Setor de Coturnicultura da Fazenda Experimental de Iguatemi (FEI) da Universidade Estadual de Maringá/UEM-PR. Foram utilizadas 360 codornas machos (Coturnix coturnix japonica) com 40 dias de idade, alojadas em gaiolas sobrepostas de arame galvanizado (38 x $25 \times 14 \mathrm{~cm}$ ). O delineamento experimental utilizado foi inteiramente casualizado, com seis tratamentos (raçãoreferência + cinco alimentos) e seis repetições de dez codornas, resultando em uma área de $95 \mathrm{~cm}^{2} /$ ave. As temperaturas médias (máxima e mínima) foram registradas diariamente dentro do galpão, cujas médias foram de $28^{\circ}$ e $17^{\circ} \mathrm{C}$, respectivamente.

Os alimentos alternativos utilizados foram aveia (grão moído), cevada (grão moído), resíduo do processamento de mandioca e semente de linhaça inteira e moída, em substituição parcial de $20 \%$ (matéria natural) à ração-referência (RR), à base de milho moído e farelo de soja (45\%). A dieta experimental (Tabela 1) foi formulada considerando-se a composição dos alimentos obtida por Rostagno et al. (2000) e as exigências nutricionais descritas pelo NRC (1994).

O período experimental teve duração de dez dias (cinco dias de adaptação + cinco dias de coleta total das excretas) e, nesse período, as aves receberam ração e água à vontade e 17 horas diárias de luz. As rações foram pesadas no início e no final do período total da coleta com a finalidade de se obter o consumo médio de ração. Foi utilizado o método tradicional de coleta total de excretas, utilizando-se óxido férrico $(2 \%)$ como marcador do início e do fim da coleta.

As gaiolas foram forradas com bandejas revestidas com plásticos, devidamente identificados, os quais foram removidos a cada coleta (intervalo de 12 horas) para a retirada das excretas. O material coletado, após retirada dos resíduos de pena, de ração e de descamação da pele das codornas, foram armazenados em congelador até o final do período total de coletas. Posteriormente, as excretas foram

Tabela 1 - Composição percentual e calculada da ração-referência (matéria natural) para codornas japonesas

Table 1 - Ingredient and calculated compositions of the reference diet (as-fed basis) for Japanese quails

\begin{tabular}{|c|c|}
\hline $\begin{array}{l}\text { Ingrediente } \\
\text { Ingredient }\end{array}$ & $\begin{array}{c}\text { Porcentagem } \\
\text { Percentage }\end{array}$ \\
\hline Milho & 62,72 \\
\hline \multicolumn{2}{|l|}{ Corn } \\
\hline Farelo de soja & 34,19 \\
\hline \multicolumn{2}{|l|}{ Soybean meal } \\
\hline Calcário & 1,23 \\
\hline \multicolumn{2}{|l|}{ Limestone } \\
\hline Fosfato bicálcico & 1,00 \\
\hline \multicolumn{2}{|l|}{ Dicalcium phosphate } \\
\hline Sal comum & 0,32 \\
\hline \multicolumn{2}{|l|}{ Salt } \\
\hline Suplemento mineral vitamínico ${ }^{1}$ & 0,45 \\
\hline \multicolumn{2}{|l|}{ Vitamin mineral supplement ${ }^{1}$} \\
\hline DL-metionina & 0,08 \\
\hline \multicolumn{2}{|l|}{ DL-methionine } \\
\hline $\mathrm{BHT}^{2}$ & 0,01 \\
\hline \multicolumn{2}{|l|}{ Antioxidant } \\
\hline Total & 100,00 \\
\hline Energia metabolizável (kcal/kg) & 2.929 \\
\hline \multicolumn{2}{|l|}{ Metabolizable energy (kca/kg) } \\
\hline Proteína bruta $(\%)$ & 21,00 \\
\hline \multicolumn{2}{|l|}{ Crude protein (\%) } \\
\hline Cálcio $(\%)$ & 0,85 \\
\hline \multicolumn{2}{|l|}{ Calcium (\%) } \\
\hline Fósforo disponível (\%) & 0,30 \\
\hline \multicolumn{2}{|l|}{ Available phosphorus (\%) } \\
\hline Metionina + cistina $(\%)$ & 0,75 \\
\hline \multicolumn{2}{|l|}{ Methionine + cystine (\%) } \\
\hline Lisina $(\%)$ & 1,10 \\
\hline \multicolumn{2}{|l|}{ Lysine (\%) } \\
\hline Cloro $(\%)$ & 0,20 \\
\hline \multicolumn{2}{|l|}{ Chloride (\%) } \\
\hline Sódio (\%) & 0,17 \\
\hline
\end{tabular}

1 Composição por kg do produto: Ca 0,213\%; Fe 1,846\%; Co 0,012\%; Cu 0,373\%; Mn 2,752\%; Zn 1,790\%; Se 0,006\%; I 0,028\%; MM 4,052\% Veículo q.s.p. $1.000 \mathrm{~g}$.- Vit. A 2.586.956 UI; Vit. D3 $612.500 \mathrm{UI}$; Vit k3 $158.261 \mathrm{mg}$; Vit.B1 75.326 mg; Vit. B2 $973.913 \mathrm{mg}$; Vit. B6 $75.326 \mathrm{mg}$; Vit. B12 2130.435 mcg; Vit .E 1521.739 mg; Ác.Pantotênico 2386.087 mg; Niacina 3766.304 mg; Vit. C 41.384 mg; Colina 117 g; Antioxidante $913.064 \mathrm{mg} / \mathrm{kg}$; Veículo q.s.p. $1.000 \mathrm{~g}$.

${ }^{1}$ Mineral and vitamin supplement - composition per kg of product: Ca $0.213 \% ; \mathrm{Fe} 1.846 \%$ Co $0.012 \% \cdot \mathrm{Cu} 0.373 \% \cdot \mathrm{Mn} 2.752 \% \cdot \mathrm{Zn} 1.790 \% \cdot \mathrm{Se} 0.006 \% \cdot 10.028 \% \cdot M M 4.052 \%$; Vehicle. Q.S.P1.000 g-Vit. A 2.586.956 Ul; Vit. D3612.500 Ul; Vit. k3158.261 mg; Vit.B1 75.326 mg; Vit.B2 973.913 mg; Vit. B675.326 mg; Vit. B122130.435 mcg; Vit. E1521.739 mg; Panthotenic acid 2386.087 mg; Niacin $3766.304 \mathrm{mg}$; Vit. C $41.384 \mathrm{mg}$; Choline $117 \mathrm{~g}$; Antioxidant $913.064 \mathrm{mg} / \mathrm{kg}$; Vehicle. Q.S.P $1.000 \mathrm{~g}$

2 Butil Hidróxi Tolueno (Antioxidante). 
descongeladas, homogeneizadas, pesadas e secas em estufa de ventilação forçada por 72 horas a $55^{\circ} \mathrm{C}$. Em seguida, foram moídas e encaminhadas para as análises de matéria seca (MS), energia bruta (EB) e nitrogênio (N). As análises laboratoriais das rações, dos alimentos e das excretas foram feitas conforme metodologia descrita por Silva \& Queiroz (2002). Os valores de EB foram determinados por meio de uma bomba calorimétrica adiabática (Parr Instruments Co.). Os valores de energia metabolizável aparente (EMA) e energia metabolizável aparente corrigida para balanço de nitrogênio $\left(\mathrm{EMA}_{\mathrm{n}}\right)$ dos alimentos foram estimados utilizando-se a equação de Matterson et al. (1965).

Os dados obtidos foram submetidos à análise de variância e as médias comparadas pelo teste Tukey a 5\% de significância, por meio do programa estatístico SAEG (1997).

\section{Resultados e Discussão}

Os resultados dos coeficientes de metabolização da energia bruta (CMEB) dos alimentos avaliados são apresentados na Tabela 2. Os CMEB da aveia moída, da cevada moída e da linhaça (inteira e moída) não diferiram entre si, mas foram superiores $(\mathrm{P}<0,05)$ aos obtidos para o resíduo de mandioca, provavelmente em razão do maior tempo de trânsito da ração contendo este alimento pelo trato digestório decorrente do menor teor de fibra bruta.
Os valores médios de EMA e EMAn dos alimentos encontram-se na Tabela 2. Os valores de EMA e EMAn obtidos para a cevada moída $(3.253,73$ e $3.198,21 \mathrm{kcal} / \mathrm{kg}$, respectivamente) foram superiores aos encontrados por Albino et al. (1986), que obtiveram valores de 3.015 e $2.968 \mathrm{kcal} / \mathrm{kg}$, ao realizarem ensaios com frangos de corte. O valor de EMAn determinado para a aveia moída foi 3.395,55 kcal $/ \mathrm{kg}$, superior ao citado pelo NRC (1994), de $2.550 \mathrm{kcal} \mathrm{EMn/kg} \mathrm{para}$ frangos de corte.

Os teores de EMA e EMAn do resíduo do processamento da mandioca, da semente de linhaça inteira e da semente de linhaça moída foram 2.312,68 e 2.316,46; 3.774,22 e 3.704,43; e $3.955,36$ e $3.929,24 \mathrm{kcal} / \mathrm{kg}$, respectivamente.

Essa diversidade nos resultados pode ser decorrente do tempo de passagem do alimento no trato digestório de codornas, de 1 a 1,5 horas em codornas e de 3 a 5 horas em galinhas, e do melhor aproveitamento da energia proveniente de fibra da ração, o que pode estar relacionado ao maior tamanho relativo do ceco, resultando em maior digestibilidade da fibra (Murakami \& Ariki, 1998).

Considerando-se que os valores de EMA e EMAn do milho para codornas japonesas são de 3.444 e $3.429 \mathrm{kcal} / \mathrm{kg}$, respectivamente (Furlan et al., 1998), e para codornas européias, de 3.134 e $3.316 \mathrm{kcal} / \mathrm{kg}$, respectivamente (Rezende et al., 2004), os alimentos avaliados neste experimento, à exceção do resíduo do processamento da mandioca, são

Tabela 2 - Valores médios de energia metabolizável aparente (EMA), energia meabolizável aparente corrigida para nitrogênio (EMAn), coeficiente de metabolização da energia bruta (CMEB) e erros-padrão dos alimentos, determinados com codornas japonesas*

Table 2 - Values of apparent metabolizable energy (AME), apparent correct (AMEn) and gross energy metabolization coeficient (GEMC) and standard errors of feedstuffs, determined with japanese quails* ( EMA

\begin{tabular}{|c|c|c|c|}
\hline $\begin{array}{l}\text { Alimento } \\
\text { Feedstuff }\end{array}$ & $\begin{array}{l}\text { EMA } \\
A M E\end{array}$ & $\begin{array}{l}\text { EMAn } \\
A M E n\end{array}$ & $\begin{array}{c}\text { CMEB }^{1} \\
\text { GEMC }\end{array}$ \\
\hline $\begin{array}{l}\text { Aveia moída } \\
\text { Milled oat }\end{array}$ & $3425,12 \pm 96,11$ & $3395,55 \pm 86,87$ & $75,37 \pm 0,53 a$ \\
\hline $\begin{array}{l}\text { Cevada moída } \\
\text { Milled barley }\end{array}$ & $3253,73 \pm 104,52$ & $3198,21 \pm 77,32$ & $75,73 \pm 0,59 a$ \\
\hline $\begin{array}{l}\text { Resíduo de mandioca } \\
\text { Cassava residue }\end{array}$ & $2312,68 \pm 175,84$ & $2316,46 \pm 157,92$ & $70,76 \pm 0,99 b$ \\
\hline $\begin{array}{l}\text { Linhaça inteira } \\
\text { Whole linssed }\end{array}$ & $3774,22 \pm 260,79$ & $3704,43 \pm 220,44$ & $76,53 \pm 1,32 a$ \\
\hline $\begin{array}{l}\text { Linhaça moída } \\
\text { Milled linseed }\end{array}$ & $3955,36 \pm 167,88$ & $3929,24 \pm 174,93$ & $76,75 \pm 0,84 a$ \\
\hline
\end{tabular}

* Valores expressos em $\mathrm{kcal} / \mathrm{kg}$ de matéria natural.

${ }^{1}$ Letras diferentes na mesma coluna diferem significativamente pelo teste Tukey $(P<0,05)$.

* Values expressed in natural matter $(\mathrm{kcal} / \mathrm{kg})$.

1 Different letters in the same column differ by Tukey test $(P<0.05)$.

passíveis de utilização em substituição ao milho em dietas para cadornas. Dessa forma, tornam-se necessários ensaios para determinação do melhor nível de substituição desses alimentos em dietas para codornas, bem como do desempenho zootécnico e da qualidade dos ovos e/ou da carne dessas aves.

\section{Conclusões}

Os CMEB (\%) e os valores de EMA e EMAn ( $\mathrm{kcal} / \mathrm{kg})$ foram de 75,37; 3.425,12 e 3.395,55 para aveia moída; 75,73; 3.253,73 e 3.198,21 para cevada moída; 70,76; 2.312,68 e 2.316,46 para resíduo do processamento da mandioca; 
76,$53 ; 3.774,22$ e $3.704,43$ para semente de linhaça inteira e 76,$75 ; 3.955,36$ e $3.929,24$ para semente de linhaça moída.

\section{Literatura Citada}

ALBINO, L.F.T.; ROSTAGNO, H.S.; FONSECA, B.J. et al. Tabela de composição de alimentos concentrados - Valores de composição química e de energia determinados com aves em diferentes idades. Revista Brasileira de Zootecnia, v.10, n.1, p.133-146, 1981.

ALBINO, L.F.T.; COELHO, R.G.M.; BRUM, R.A.P. et al. Determinação da energia metabolizável de alguns alimentos para aves. In: CONGRESSO BRASILEIRO DE AVICULTURA, 1985, Brasília. Anais... Brasília: s.n., 1985. p.77.

ALBINO, L.F.T.; FIALHO, E.T.; BLUME, E. Energia metabolizável e composição química de alguns alimentos para frangos de corte. Revista Brasileira de Zootecnia, v.15, n.3, p.184-192, 1986 .

ALLEN, R.M.D. Feedstuffs ingredient analysis table. Feedstuffs, v.56, n.30, p.25-30, 1992.

FURLAN, A.C.; ANDREOTTI, M.O.; MURAKAMI, A.E. et al. Valores energéticos de alguns alimentos determinados com codornas japonesas (Coturnix coturnix japonica). Revista Brasileira de Zootecnia, v.27, n.6, p.1147-1150, 1998.

GARCIA, E.A.; PIZZOLANTE, C.C. Nutrição de codornas para postura. In: SIMPÓSIO INTERNACIONAL, 2., CONGRESSO BRASILEIRO DE COTURNICULTURA, 1., 2004, Lavras. Anais... Lavras: Universidade Federal de Lavras, 2004. p.65-76.

LEANDRO, N.S.M.; STRINGHINI, J.H.; CAFÉ, M.B. et al. Efeito da granulometria do milho e do farelo de soja sobre o desempenho de codornas japonesas. Revista Brasileira de Zootecnia, v.30, n.4, p.1266-1271, 2001.

MATTERSON, L.B.; POTTER, L.M.; STUTZ, T. et al. The metabolizable energy of feed ingredients for chickens. Research Reports, v.7, p.3-11, 1965.

MURAKAMI, A.E.; FURLAN, A.C.; SCAPINELLO, C. et al. Composição química e valor energético da semente e do farelo de canola para aves. In: CONFERÊNCIA APINCO DE CIÊNCIA E TECNOLOGIA AVÍCOLA, 1995, Curitiba. Anais... Curitiba: Fundação APINCO de Ciência e Tecnologia Avícolas, 1995. p.17-18.
MURAKAMI, A.E.; ARIKI, J. Produção de codornas japonesas. Jaboticabal: Fundação de Apoio a Pesquisa, Ensino e Extensão, 1998. 79p.

MURAKAMI, A.E.; FURLAN, A.C. Pesquisas na nutrição e alimentação de codornas em postura no Brasil. In: SIMPÓSIO INTERNACIONAL DE COTURNICULTURA, 1., 2002, Lavras, MG. Anais... Lavras: Universidade Federal de Lavras, 2002. p.113-120.

MUZTAR, J.A.; SLINGER, S.J. The true metabolizable energy and amino acid content of candle, altex and regent canola meals. Canadian Journal Animal Science, v.62, n.2, p.521-525, 1982.

NATIONAL RESEARCH COUNCIL - NRC. Nutrient requirements of poultry. 9.ed. Washington, D.C.: National Academy of Science, 1994. 155p.

REZENDE, M.J.M.; TORRES, A.F.; OLIVEIRA, L.Q.M. et al Determinação dos valores de energia metabolizável de sete alimentos em codornas européias. In: SIMPÓSIO INTERNACIONAL, 2., CONGRESSO BRASILEIRO DE COTURNICULTURA, 1. 2004, Lavras. Anais... Lavras: Universidade Federal de Lavras, 2004.p. 211

ROSTAGNO, H.S.; ALBINO, L.F.T.; DONZELE, J.L. et al. Composição de alimentos e exigências nutricionais de aves e suínos (Tabelas Brasileiras). Viçosa, MG: Universidade Federal de Viçosa, 2000. 141p.

SILVA, D.J.; QUEIROZ, A.C. Análise de alimentos (Métodos químicos e biológicos). 3.ed. Viçosa, MG: Universidade Federal de Viçosa, 2002. 235p.

UNIVERSIDADE FEDERAL DE VIÇOSA - UFV. SAEG - Sistema de Análises Estatísticas e Genética. Viçosa, MG: 1997. 